\title{
Long-term reliability of the Figaro TGS 2600 solid-state methane sensor under low-Arctic conditions at Toolik Lake, Alaska
}

\author{
Werner Eugster $^{1}$, James Laundre ${ }^{2}$, Jon Eugster ${ }^{3, a}$, and George W. Kling ${ }^{4}$ \\ ${ }^{1}$ ETH Zurich, Department of Environmental Systems Science, Institute of Agricultural Sciences, \\ Universitätstrasse 2, 8092 Zurich, Switzerland \\ ${ }^{2}$ The Ecosystem Center, Marine Biology Laboratory, Woods Hole, MA 02543, USA \\ ${ }^{3}$ University of Zurich, Institute of Mathematics, Winterthurerstrasse 190, 8057 Zurich, Switzerland \\ ${ }^{4}$ University of Michigan, Department of Ecology \& Evolutionary Biology, Ann Arbor, MI 48109-1085, USA \\ anow at: School of Mathematics, The University of Edinburgh, Edinburgh, UK
}

Correspondence: Werner Eugster (eugsterw@ethz.ch)

Received: 24 October 2019 - Discussion started: 11 December 2019

Revised: 31 March 2020 - Accepted: 11 April 2020 - Published: 27 May 2020

\begin{abstract}
The TGS 2600 was the first low-cost solid-state sensor that shows a response to ambient levels of $\mathrm{CH}_{4}$ (e.g., range $\approx 1.8-2.7 \mu \mathrm{mol} \mathrm{mol}^{-1}$ ). Here we present an empirical function to correct the TGS 2600 signal for temperature and (absolute) humidity effects and address the long-term reliability of two identical sensors deployed from 2012 to 2018. We assess the performance of the sensors at $30 \mathrm{~min}$ resolution and aggregated to weekly medians. Over the entire period the agreement between TGS-derived and reference $\mathrm{CH}_{4}$ mole fractions measured by a high-precision Los Gatos Research instrument was $R^{2}=0.42$, with better results during summer $\left(R^{2}=0.65\right.$ in summer 2012). Using absolute instead of relative humidity for the correction of the TGS 2600 sensor signals reduced the typical deviation from the reference to less than $\pm 0.1 \mu \mathrm{mol} \mathrm{mol}^{-1}$ over the full range of temperatures from -41 to $27^{\circ} \mathrm{C}$. At weekly resolution the two sensors showed a downward drift of signal voltages indicating that after 10-13 years a TGS 2600 may have reached its end of life. While the true trend in $\mathrm{CH}_{4}$ mole fractions measured by the high-quality reference instrument was $10.1 \mathrm{nmol} \mathrm{mol}^{-1} \mathrm{yr}^{-1}$ (2012-2018), part of the downward trend in sensor signal (ca. 40\%-60\%) may be due to the increase in $\mathrm{CH}_{4}$ mole fraction because the sensor voltage decreases with increasing $\mathrm{CH}_{4}$ mole fraction. Weekly median diel cycles tend to agree surprisingly well between the TGS 2600 and reference measurements during the snowfree season, but in winter the agreement is lower. We suggest developing separate functions for deducing $\mathrm{CH}_{4}$ mole frac-
\end{abstract}

tions from TGS 2600 measurements under cold and warm conditions. We conclude that the TGS 2600 sensor can provide data of research-grade quality if it is adequately calibrated and placed in a suitable environment where crosssensitivities to gases other than $\mathrm{CH}_{4}$ are of no concern.

\section{Introduction}

Low-cost trace gas sensors open new deployment opportunities for environmental observations. Still, their long-term performance in real-world applications is largely unknown, and thus, scientific research with such low-cost sensors is challenged with a high risk of failure and questionable data quality. Hence low-cost sensors are only considered as a complementary source of information on air quality (e.g., Lewis et al., 2018; Castell et al., 2017). Here we report on a 7-year (2012-2018) deployment of two low-cost Figaro TGS 2600 methane $\left(\mathrm{CH}_{4}\right)$ sensors during summer and winter conditions in the relatively harsh low-Arctic climate of northern Alaska to explore the long-term stability and reliability of $\mathrm{CH}_{4}$ mole fraction estimates. The sensors were previously deployed over Toolik Lake during the ice-free season in 2011 (Eugster and Kling, 2012), where similar values between TGS-derived and reference $\mathrm{CH}_{4}$ mole fractions were only found if measurements were integrated over at least $6 \mathrm{~h}$ or if they were aggregated to mean diel cycles over the season. Other studies have deployed the same sensor type in 
complex rural and urban environments along the Colorado Front Range (Collier-Oxandale et al., 2018), in an oil and gas production region (Greeley, Colorado; Casey et al., 2019), and in urban south Los Angeles (Shamasunder et al., 2018). An application on an unmanned aerial vehicle, however, did not successfully detect $\mathrm{CH}_{4}$ hotspots (Falabella et al., 2018). These are all pioneering studies but are mostly restricted to a few days to months of measurements. Thus, our study is the first long-term comparison of high-precision measurements to those from $\mathrm{CH}_{4}$ sensitive, low-cost sensors under challenging climatic conditions.

Typically, new sensors are first calibrated under controlled conditions in a laboratory environment. Extensive calibration tests with a similar low-cost sensor (Figaro TGS2611E00) from the same manufacturer as our TGS 2600 have been carried out by van den Bossche et al. (2017). Despite the care taken in their calibration effort, the residual $\mathrm{CH}_{4}$ mole fraction after calibration was still on the order of $\pm 1.7 \mu \mathrm{mol} \mathrm{mol}^{-1}$, which is acceptable for chamber flux measurements, for example, over water (as done by, e.g., Duc et al., 2019) but not sufficient to measure ambient atmospheric mole fractions, which are of the same order of magnitude as the calibration uncertainty. The issue of important differences between laboratory assessments of low-cost sensors and their real-world performance is well known and typically relates to different data correction and calibration approaches in real-world rather than laboratory applications (Lewis et al., 2018). Hence we decided to use outdoor measurements obtained over a wide range of temperatures and relative humidity - the major cross-sensitivities experienced by such sensors - and derive a calibration function via parameter extraction using this dataset. Our goals were thus to (1) establish a statistical calibration function from field measured conditions that can also be used in different contexts to linearize the TGS 2600 sensor signal (which then can still be fine-tuned with a two-point calibration in a specific application); (2) assess the reliability of the TGS 2600 low-cost sensor under winter and summer conditions in the Arctic over 7 years of continuous deployment; and (3) explore potential improvements for sensor data processing, which includes (3a) wind effects that are neglected in laboratory environments and (3b) artificial neural networks (ANNs) to find out whether results can be improved over standard statistical regression methods for calibration of the sensor.

\section{Material and methods}

\subsection{Study site}

Field measurements were carried out at the Toolik wet sedge site (TWE; 68 $37^{\prime} 27.62^{\prime \prime} \mathrm{N}, 149^{\circ} 36^{\prime} 08.10^{\prime \prime} \mathrm{W}$; $728.14 \mathrm{~m}$ elevation, WGS 84 datum) where seasonal eddy covariance flux measurements were carried out during the summer seasons of 2010-2015 and partially during winters starting in 2014

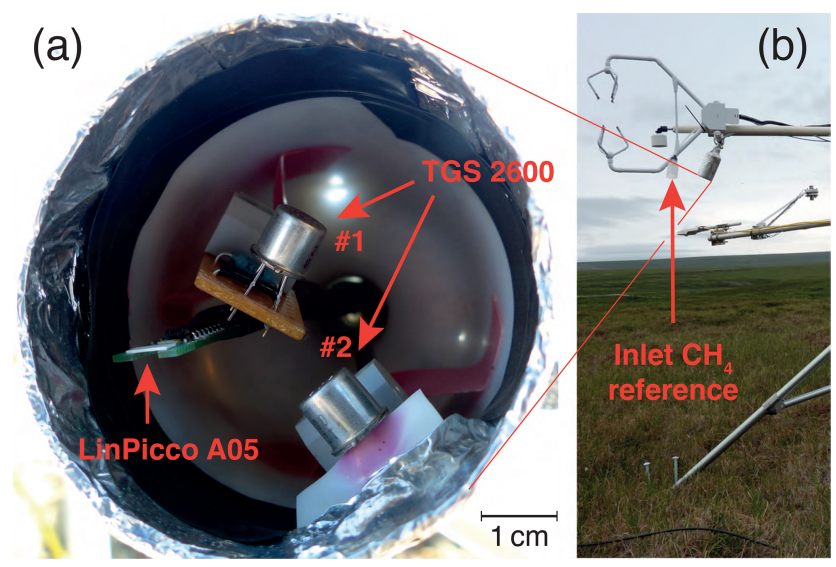

Figure 1. Two TGS 2600 trace gas sensors and the LinPicco A05 temperature and relative humidity sensor (a) inside the weather protection and (b) the mounting position of the TGS weather protection and reference $\mathrm{CH}_{4}$ gas inlets at the Toolik wet sedge eddy covariance flux site.

until 15 June 2016, with the continuation as a meteorological station until present. The site is a wetland that is a local source of $\mathrm{CH}_{4}$ with a flux rate that is roughly 1 order of magnitude stronger than adjacent Toolik Lake, where the Eugster and Kling (2012) study was performed. The site is a wet graminoid tundra dominated by sedge species, namely cotton grass (Eriophorum angustifolium) and Carex aquatilis (Walker and Everett, 1991).

\subsection{Instrumentation and measurements}

Two Figaro TGS 2600 sensors (Figaro, 2005a, b) that were already deployed over Toolik Lake (TOL) during the ice-free season in 2011 (Eugster and Kling, 2012) were installed at the TWE site in late June 2012 (Fig. 1). Sensor 1 is the primary sensor used in this study, whereas sensor 2 was only used as a replicate to simplify assessing potential problems with sensor 1. Because no such problems occurred, we will focus only on the results obtained with sensor 1 except in Sect. 3.2, where we used both sensors to assess their performance at weekly time resolution. The TGS 2600 is a highsensitivity solid-state sensor for the detection of air contaminants (Figaro, 2005a). It is sensitive to methane at low mole fractions but also to hydrogen, carbon monoxide, isobutane, and ethanol. It is the only low-cost solid-state sensor that we are aware of for which the manufacturer indicates a sensitivity to methane even under ambient $\left(\approx 2 \mu \mathrm{mol} \mathrm{mol}^{-1}\right)$ methane mole fractions, whereas most other sensors are only sensitive at mole fractions that exceed ambient levels by at least 1 or 2 orders of magnitude. This high sensitivity to lowmethane mole fractions comes at the expense that no specific molecular filter prevents the other components from reaching the sensor surface. Thus, our considerations made here assume that deployment is made in an area like the Arctic, 
where levels of carbon monoxide, isobutane, ethanol, and hydrogen are rather constant and do not vary as strongly as methane so that the sensor signal can be interpreted as a first approximation of a methane mole fraction signal. For additional details on the TGS 2600 sensor the reader is referred to Eugster and Kling (2012).

The TWE site receives line power from the Toolik Field Station (TFS) power generator. During the snow- and icefree summer season (typically late June to mid-August) measurements are almost interruption-free, but during the cold season (typically September to late May) longer power interruptions limit the winter data coverage. Nevertheless, this is the first study that provides low-cost sensor methane mole fraction measurements over a temperature range from Arctic winter temperatures of $-41{ }^{\circ} \mathrm{C}$ to a relatively balmy $27^{\circ} \mathrm{C}$ during short periods of the Arctic summer. Reference $\mathrm{CH}_{4}$ dry mole fractions were measured by a Fast Methane Analyzer (FMA, Los Gatos Research, Inc., San Jose, CA, USA; years 2012-2016), which was replaced by a Fast Greenhouse Gas Analyzer (FGGA, Los Gatos Research, Inc., San Jose, CA, USA; since 2016) for combined $\mathrm{CH}_{4}, \mathrm{CO}_{2}$, and $\mathrm{H}_{2} \mathrm{O}$ dry mole fraction measurements. Until 18 June 2016 the $\mathrm{CH}_{4}$ mole fractions were calculated as $1 \mathrm{~min}$ averages from the raw eddy covariance flux data files. We report all gas mole fractions in micromoles per mole or nanomoles per mole. The FMA and FGGA sampling rate was set to $20 \mathrm{~Hz}$, and the flow rate of sample air was ca. $20 \mathrm{~L} \mathrm{~min}^{-1}$. After the termination of eddy covariance flux measurements, the FGGA measurements were continued with the instrument's internal pump (flow rate ca. $0.65 \mathrm{~L} \mathrm{~min}^{-1}$ ) with $1 \mathrm{~Hz}$ raw data sampling. In addition to digital recording, the $\mathrm{CH}_{4}$ signal was converted to an analog voltage that was recorded on a CR23X data logger (Campbell Scientific Inc., CSI, Logan, UT, USA). The same data logger also recorded air temperature, relative humidity (HMP45AC, CSI), wind speed, and wind direction (034B Windset, MetOne, Grants Pass, OR, USA) as well as ancillary meteorological and soil variables not used in this study. The factory-calibrated HMP45AC sensor head was exchanged for a newly calibrated one ca. every 3 years to minimize long-term drift effects in temperature and relative humidity measurements (James Laundre, personal communication, 2020). Sensors were measured every $5 \mathrm{~s}$, and $1 \mathrm{~min}$ averages were stored on the logger. These data were then screened for outliers and instrumental errors and failures, and $30 \mathrm{~min}$ averages were calculated for the present analysis.

Both FMA and the later FGGA analyzers were used for eddy covariance applications, and thus the instruments were not calibrated as frequently as is done in applications for the Global Atmosphere Watch network (WMO, 2001). Both sensors were more accurate than the available calibration $\mathrm{CH}_{4}$ gases at TFS. In 2015 it was possible for the first time to use an NOAA (National Oceanographic and Atmospheric Administration, Boulder, CO, USA) reference gas cylinder (no. CB09837) to fine-tune the FGGA. This was typically done in the early summer season, when field personnel arrived at TFS (late May).

Because the TGS 2600 sensors only show a weak response to $\mathrm{CH}_{4}$ but are highly sensitive to temperature and humidity, a LinPicco A05 Basic sensor (IST Innovative Sensor Technology, Wattwil, Switzerland) was added next to the TGS 2600 (see Fig. 1). The A05 is a capacitive humidity module that also has a Pt1000 platinum $1 \mathrm{k} \Omega$ thermistor on board to measure ambient temperature. The relative humidity output by the A05 is a linearized voltage in the range of $0-5 \mathrm{~V}$, and the Pt1000 thermistor was measured in three-wire half-bridge mode using an excitation voltage of $4.897 \mathrm{~V}$.

\subsection{Calculations}

Before analyses the data were processed in the following way: (1) outliers were removed (2) relative humidities greater than $105 \%$ (accuracy of capacitive humidity sensors) were deleted, and (3) reference $\mathrm{CH}_{4}$ mole fractions obtained from the FGGA (since 2016) were filtered based on hard boundaries of housekeeping variables available for quality control. For the latter we used the following hard boundaries for filtering: (a) sample cell pressure had to be in the range of 130-143 Torr and (b) the instrument-specific ringdown time of the laser for $\mathrm{CH}_{4}$ measurements had to be in the range of 13-17 ms. The accepted reference $\mathrm{CH}_{4}$ mole fractions were thus all measured in the narrow range of cell pressures between 139.7 and 140.3 Torr and laser ringdown times between 14.02 and $14.94 \mathrm{~ms}$, which indicates best performance of the analyzer. Before 2016 (FMA instrument) these housekeeping variables were not recorded.

The basic principle of operation of the TGS 2600 sensor was described in detail by Eugster and Kling (2012). The methane sensing mechanisms of different active materials used in solid-state sensors were described by Aghagoli and Ardyanian (2018). The TGS 2600 uses an $\mathrm{SnO}_{2}$ microcrystal surface (Figaro, 2005b). Whereas the manufacturer defines the sensor signal as $R_{\mathrm{S}} / R_{0}$, the ratio of the electrical resistance $R_{\mathrm{S}}$ of the heated sensor material surface normalized over its resistance $R_{0}$ in the air under absence of $\mathrm{CH}_{4}$, $\mathrm{Hu}$ et al. (2016) define the sensor signal as the ratio between $R_{\mathrm{S}}$ and $R_{\mathrm{g}}$, the resistance of the surface in the pure gas of interest (here $\mathrm{CH}_{4}$ ). In all cases, considerations of technical sensor information are made for high mole fractions of $\mathrm{CH}_{4}$ (e.g., $200 \mu \mathrm{mol} \mathrm{mol}^{-1}$ ) for an $\mathrm{SnO}_{2}$ surface according to Hu et al. (2016), not for ambient mole fractions in the typical range of $1.7-4 \mu \mathrm{mol} \mathrm{mol}^{-1}$ (or less). Hence, some adaptations are always necessary because present-day sensors are not yet designed for such low mole fractions. In order to simplify calculations compared to what we presented in Eugster and Kling (2012) - which closely followed the technical information provided by the manufacturer (Figaro, 2005a, b) we define the sensor signal as $S_{\mathrm{c}}=R_{\mathrm{S}} / R_{0}$ but with $R_{0}$ arbitrarily set to the resistance observed when the sensor delivers $V_{0}=0.8 \mathrm{~V}$ output at $V_{\mathrm{c}}=5.0 \mathrm{~V}$ supply voltage. The high- 
est voltages measured at TWE were 0.7501 and $0.7683 \mathrm{~V}$ from sensors 1 and 2, respectively (which theoretically corresponds to the lowest $\mathrm{CH}_{4}$ mole fractions). With these assumptions the sensor signal $S_{\mathrm{c}}$ can easily be approximated as a function of the inverse of the measured TGS signal voltage $V_{\mathrm{s}}$

$S_{\mathrm{c}}=\frac{R_{\mathrm{s}}}{R_{0}} \approx 0.952381 \cdot \frac{1}{V_{\mathrm{s}}}-0.1904762$.

The full derivation is

$$
\begin{aligned}
\frac{R_{\mathrm{S}}}{R_{0}} & =\frac{\frac{V_{\mathrm{c}} \cdot R_{\mathrm{L}}}{V_{\mathrm{s}}}-R_{\mathrm{L}}}{\frac{V_{\mathrm{c}} \cdot R_{\mathrm{L}}}{V_{0}}-R_{\mathrm{L}}}=\frac{\frac{V_{\mathrm{c}} \cdot R_{\mathrm{L}}-V_{\mathrm{s}} \cdot R_{\mathrm{L}}}{V_{\mathrm{s}}}}{\frac{V_{\mathrm{c}} \cdot R_{\mathrm{L}}-V_{\mathrm{s}} \cdot R_{\mathrm{L}}}{V_{0}}}= \\
& =\frac{V_{0}\left(V_{\mathrm{c}}-V_{\mathrm{s}}\right) R_{\mathrm{L}}}{V_{\mathrm{s}}\left(V_{\mathrm{c}}-V_{0}\right) R_{\mathrm{L}}}=\frac{V_{0}\left(V_{\mathrm{c}}-V_{\mathrm{s}}\right)}{V_{\mathrm{s}}\left(V_{\mathrm{c}}-V_{0}\right)}= \\
& =\frac{V_{0}}{V_{\mathrm{c}}-V_{0}}\left(\frac{V_{\mathrm{c}}}{V_{\mathrm{s}}}-1\right)=\frac{1}{V_{\mathrm{s}}} \cdot \frac{V_{\mathrm{c}} \cdot V_{0}}{V_{\mathrm{c}}-V_{0}}-\frac{V_{0}}{V_{\mathrm{c}}-V_{0}} .
\end{aligned}
$$

Here $R_{\mathrm{L}}$ is the load resistor over which $V_{\mathrm{S}}$ is measured (see Figaro, 2005a, or Eugster and Kling, 2012, for more details) but which can be eliminated in this algebraic simplification.

To compute absolute humidity, we used the Magnus equation to estimate saturation vapor pressure $e_{\text {sat }}(\mathrm{in} \mathrm{hPa}$ ) at ambient temperature $T_{\mathrm{a}}\left(\mathrm{in}^{\circ} \mathrm{C}\right)$,

$e_{\text {sat }}=6.107 \times 10^{a \cdot T_{\mathrm{a}} /\left(b+T_{\mathrm{a}}\right)}$,

with coefficients $a=7.5$ and $b=235.0$ for $T_{\mathrm{a}} \geq 0{ }^{\circ} \mathrm{C}$ and $a=9.5$ and $b=265.5$ for $T_{\mathrm{a}}<0{ }^{\circ} \mathrm{C}$.

Actual vapor pressure $e(\mathrm{hPa})$ was then determined as

$e=e_{\mathrm{sat}} \cdot \frac{\mathrm{RH}}{100 \%}$,

with relative humidity RH in percent and converted to absolute humidity $\rho_{\mathrm{v}}\left(\mathrm{kg} \mathrm{m}^{-3}\right)$ with

$\rho_{\mathrm{v}}=\frac{e}{T_{\mathrm{a}}+273.15} \cdot \frac{p}{p-e} \cdot \frac{100}{R_{\mathrm{v}}} \approx 0.217 \cdot \frac{e}{T_{\mathrm{a}}+273.15}$,

with $p$ being atmospheric pressure $(\mathrm{hPa})$ and $R_{\mathrm{V}}$ the gas constant for water vapor $\left(461.53 \mathrm{~J} \mathrm{~kg}^{-1} \mathrm{~K}^{-1}\right)$.

\subsection{Statistical analyses}

Statistical analyses were performed with $\mathrm{R}$ version 3.5.2 ( $\mathrm{R}$ Core Team, 2018). Trend analyses were performed for both trend in $\mathrm{CH}_{4}$ mole fraction and drift of TGS 2600 measurements using the Mann-Kendall trend test implemented in the rkt package that is based on Marchetto et al. (2013). The annual linear trend (or drift) was calculated using the robust Theil-Sen estimator (Akritas et al., 1995) using weekly median values, and the significance of the trend (or drift) was assessed using Kendall's $\tau$ parameter. All trend and drift estimates were significant at $p<0.05$. The highest two-sided $p$ value of the presented results was $p=0.000054$, and thus

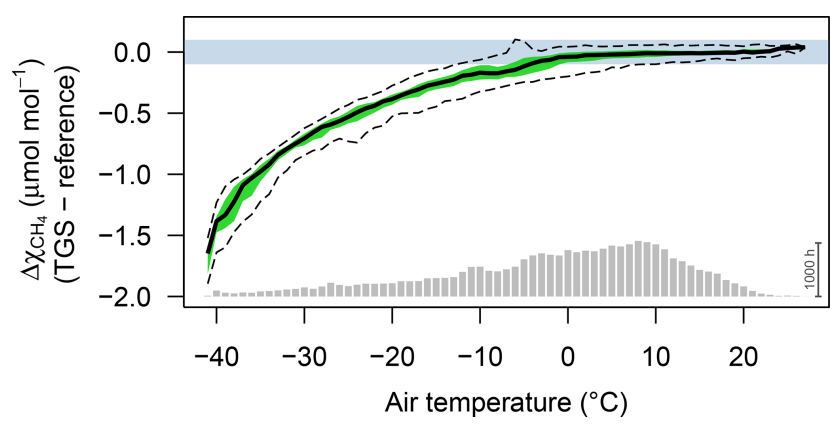

Figure 2. Difference between TGS 2600 and reference $\mathrm{CH}_{4}$ measurements (30 min averages) as a function of air temperature when using the Eugster and Kling (2012) conversion. Agreement was good when ambient temperature was above freezing. The horizontal color bar shows the $\pm 0.1 \mu \mathrm{mol} \mathrm{mol}{ }^{-1}$ range around a perfect agreement. The green band shows the interquartile range of bin-averaged differences (TGS 2600 sensor 1), and dashed lines show the extent of the $95 \%$ confidence intervals. Gray bars at the bottom show the number of $30 \mathrm{~min}$ averages in each bin. The scale bar $(1000 \mathrm{~h})$ on the right specifies their size.

no detailed information on $p$ values is given when statistical significance of trends or drift is mentioned in the following.

For assessing the quality of the proposed calculation of $\mathrm{CH}_{4}$ mole fractions from TGS 2600 sensors we inspected weekly aggregated data using four key indicators:

Bias. This is the mean of the difference of each $30 \mathrm{~min}$ averaged pair of $\mathrm{CH}_{4}$ mole fractions in micromoles per mole, $\mathrm{CH}_{4, \mathrm{TGS}}-\mathrm{CH}_{4, \text { ref }}$.

Stability. This is the bias expressed as a percent deviation from the reference $\mathrm{CH}_{4}$ mole fraction, $\left(\mathrm{CH}_{4, \mathrm{TGS}}-\right.$ $\left.\mathrm{CH}_{4, \text { ref }}\right) / \mathrm{CH}_{4, \text { ref }} \cdot 100 \%$.

Variability. This is the mean relative deviation of the $95 \%$ confidence interval (CI) observed with the TGS 2600 sensor from the corresponding $95 \% \mathrm{CI}$ of the $\mathrm{CH}_{4}$ reference measurements (in percent), $\left(\mathrm{CI}_{95} \%, \mathrm{TGS} / \mathrm{CI}_{95} \%\right.$,ref -1$) \cdot 100 \%$.

Correlation of median diel cycles. Pearson's productmoment correlation coefficient between hourly aggregated median diel cycles of $\mathrm{CH}_{4}$ measured by the TGS 2600 and reference instruments.

In addition to conventional linear model fits (least square method) we used an ANN approach. This was performed in Python 3.7.1 using MLPRegressor from sklearn.neural_network version 0.20.2 (Pedregosa et al., 2011). We used a network with four hidden layers of sizes $500,100,50$, and 5 , respectively, and an adaptive learning rate. Learning was done with the data obtained during the calibration period 2014-2016, whereas the remaining years 2012-2013 and 2017-2018 were used for validation. 

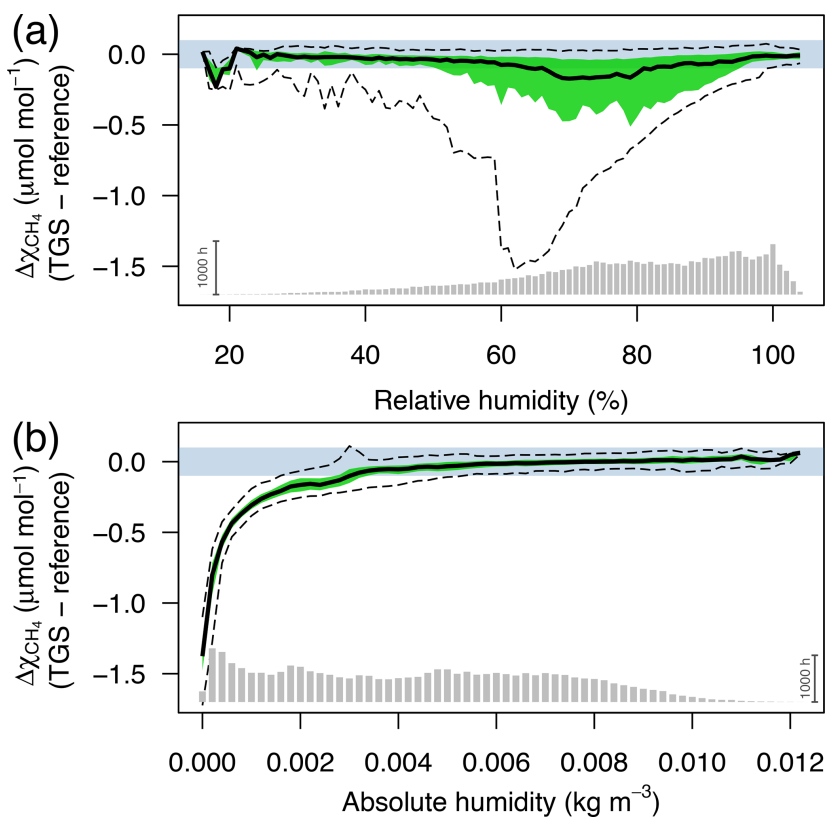

Figure 3. Difference between TGS 2600 and reference $\mathrm{CH}_{4}$ measurements (30 min averages) as a function of (a) relative humidity (in \%) and (b) absolute humidity (in $\mathrm{kg} \mathrm{m}^{-3}$ ). The horizontal color bar shows the $\pm 0.1 \mu \mathrm{mol} \mathrm{mol}{ }^{-1}$ range around a perfect agreement. The green band shows the interquartile range of bin-averaged differences (TGS 2600 sensor 1), and dashed lines show the extent of the $95 \%$ confidence intervals. Gray bars at the bottom show the number of $30 \mathrm{~min}$ averages in each bin. The scale bar $(1000 \mathrm{~h})$ on the right specifies their size.

\section{Results and discussion}

$\mathrm{CH}_{4}$ mole fractions estimated from TGS 2600 measurements during the cold seasons differed strongly from the reference measurements when the Eugster and Kling (2012) approach was used (not shown); that approach translated the information from the technical specifications of the TGS 2600 sensor (Figaro, 2005a, b) to outdoor applications. The agreement with the $\mathrm{CH}_{4}$ reference measurements was within $\pm 0.1 \mu \mathrm{mol} \mathrm{mol}^{-1}$ with temperatures above freezing (Fig. 2) but not so during cold conditions $\left(T_{\mathrm{a}}<0^{\circ} \mathrm{C}\right)$. The differences between TGS estimates and $\mathrm{CH}_{4}$ reference measurements were largest with the Eugster and Kling (2012) approach when relative humidity was between $50 \%$ and $90 \%$ (Fig. 3a). When converting relative humidity to absolute humidity, the results became satisfactory for absolute humidity values greater than $0.004 \mathrm{~kg} \mathrm{~m}^{-3}$ (Fig. 3b). Using absolute humidity in place of relative humidity for the correction of the TGS 2600 was already attempted by Collier-Oxandale et al. (2018); this contrasts with the manufacturer's suggestion (Figaro, 2005a). Because absolute humidity above $0.004 \mathrm{~kg} \mathrm{~m}^{-3}$ is only possible at temperatures above $0^{\circ} \mathrm{C}$ it appears quite obvious that temperature and humidity corrections of solid-state sensors most likely do not relate to rela- tive humidity but to either actual vapor pressure (in $\mathrm{hPa}$ ) or absolute humidity (in $\mathrm{kg} \mathrm{m}^{-3}$ ). In all tested models absolute humidity performed marginally better than vapor pressure or mixing ratio (measured by $R^{2}$; not shown); hence we suggest the following model and parameterization to estimate $\mathrm{CH}_{4}$ mole fractions in micromoles per mole from TGS 2600 signal voltage measurements:

$$
\begin{aligned}
\mathrm{CH}_{4}= & 1.425+0.12 S_{\mathrm{c}}+0.375 / S_{\mathrm{c}}-0.0065 T_{\mathrm{a}}+ \\
& +53.3 \rho_{\mathrm{v}}+0.0022 S_{\mathrm{c}} \cdot T_{\mathrm{a}}-0.0017 T_{\mathrm{a}} / S_{\mathrm{c}}+ \\
& +4.9 S_{\mathrm{c}} \cdot \rho_{\mathrm{v}}-67.4 \rho_{\mathrm{v}} / S_{\mathrm{c}}-0.39 S_{\mathrm{c}} \cdot T_{\mathrm{a}} \cdot \rho_{\mathrm{v}} \\
& +1.15 T_{\mathrm{a}} \cdot \rho_{\mathrm{v}} / S_{\mathrm{c}},
\end{aligned}
$$

with $S_{\mathrm{c}}$ being the dimensionless sensor signal (see Eq. 1), $T_{\mathrm{a}}$ the ambient air temperature in ${ }^{\circ} \mathrm{C}$, and $\rho_{\mathrm{v}}$ the absolute humidity in kilograms per cubic meter. The parameter estimates were derived from the entire 2012-2018 dataset for TGS sensor 1 (Table 1, "entire period"). For other sensors the result from Eq. (2) can be considered as a linearized signal that can be fine-tuned with a sensor-specific two-point calibration as suggested in Sect. 3.4 of Eugster and Kling (2012).

The linear model in Eq. (2) was derived from a suite of candidate models including interactions among predictors and quadratic terms of each variable, and then stepwise elimination using the stepAIC function in the MASS package of $\mathrm{R}$ was employed to find the model with the lowest AIC (Akaike's information criterion). Unless explicitly mentioned, we analyzed $\mathrm{CH}_{4}$ mole fractions computed with Eq. (2) using the parameters obtained from all data measured by TGS 2600 sensor 1 . Only in the direct comparison with the ANN (Sect. 3.1) did we determine an additional parameter set using the same calibration period as the ANN used (Sect. 2.4), making a direct comparison of performance in validation possible.

If ambient temperature influences the signal of the TGS 2600 in such a way as expected from the technical documentation (Figaro, 2005a, b), then wind speed could be a third factor influencing the conversion from TGS 2600 sensor voltages to $\mathrm{CH}_{4}$ mole fractions. To investigate this additional factor, we produced a heat loss model, assuming that the sensor correction is related to the cooling of the heated surface of the solid-state sensor, which has a nominal surface temperature $T_{\mathrm{S}}$ of $400^{\circ} \mathrm{C}$ (Falabella et al., 2018). This is the typical operation temperature of $\mathrm{SnO}_{2}-\mathrm{Ni}_{2} \mathrm{O}_{3}$ sensors $(\mathrm{Hu}$ et al., 2016). Our candidate model for heat loss (HL in W) was

$\mathrm{HL} \sim \xi \cdot \bar{u}^{2} \cdot\left(T_{\mathrm{s}}-T_{\mathrm{a}}\right) \cdot\left(\rho_{\mathrm{d}} \cdot C_{\mathrm{d}}+\rho_{\mathrm{v}} \cdot C_{\mathrm{v}}\right)$,

with $\bar{u}$ being mean horizontal wind speed $\left(\mathrm{m} \mathrm{s}^{-1}\right), T_{\mathrm{S}}$ and $T_{\mathrm{a}}$ the sensor surface and ambient air temperature $(\mathrm{K})$, respectively, $\rho_{\mathrm{d}}$ the density of dry air $\left(\mathrm{kg} \mathrm{m}^{-3}\right), \rho_{\mathrm{v}}$ the absolute humidity $\left(\mathrm{kg} \mathrm{m}^{-3}\right)$, and $C_{\mathrm{d}}$ and $C_{\mathrm{v}}$ the heat capacity of dry air and water vapor, respectively $\left(\mathrm{J} \mathrm{kg}^{-1} \mathrm{~K}^{-1}\right)$. The scaling coefficient $\xi$ is a best-fit model parameter (units: s m). 
Table 1. Goodness of fit of TGS 2600 (sensor 1)-derived $\mathrm{CH}_{4}$ mole fractions (30 min averages) obtained from a linear model using air temperature and absolute humidity (Eq. 2), a heat loss model (Eq. 3), and an artificial neural network (ANN). For the goodness of fit the coefficient of determination $\left(R^{2}\right)$ and the root mean square error (RMSE) of the residuals are reported for the overall model and separately for warm and cold conditions. The parametrization of the linear model given in Eq. (2) used the entire $2012-2018$ period. For a more rigorous model test, all three approaches were calibrated with the data measured in years 2014-2016, and the remaining data (2012-2013 and 2017-2018) were used for validation.

\begin{tabular}{|c|c|c|c|c|c|c|c|}
\hline & \multicolumn{3}{|c|}{ Linear model } & \multicolumn{2}{|c|}{ Heat loss model } & \multicolumn{2}{|c|}{ Artificial neural network } \\
\hline & Entire period & Calibration & Validation & Calibration & Validation & Calibration & Validation \\
\hline \multicolumn{8}{|l|}{ Overall } \\
\hline$R^{2}$ & 0.424 & 0.447 & 0.207 & 0.166 & 0.284 & 0.311 & 0.282 \\
\hline $\operatorname{RMSE}\left(\mu \mathrm{mol} \mathrm{mol}{ }^{-1}\right)$ & 0.030 & 0.026 & 0.041 & 0.032 & 0.046 & 0.030 & 0.043 \\
\hline \multicolumn{8}{|c|}{ Warm conditions $\left(T_{\mathrm{a}} \geq 0{ }^{\circ} \mathrm{C}\right)$} \\
\hline$R^{2}$ & 0.476 & 0.518 & 0.288 & 0.180 & 0.181 & 0.278 & 0.265 \\
\hline $\operatorname{RMSE}\left(\mu \mathrm{mol} \mathrm{mol}{ }^{-1}\right)$ & 0.027 & 0.026 & 0.032 & 0.034 & 0.039 & 0.032 & 0.036 \\
\hline \multicolumn{8}{|c|}{ Cold conditions $\left(T_{\mathrm{a}}<0^{\circ} \mathrm{C}\right)$} \\
\hline$R^{2}$ & 0.322 & 0.345 & 0.034 & 0.157 & 0.055 & 0.314 & 0.092 \\
\hline $\operatorname{RMSE}\left(\mu \mathrm{mol} \mathrm{mol}^{-1}\right)$ & 0.033 & 0.027 & 0.052 & 0.031 & 0.055 & 0.028 & 0.053 \\
\hline
\end{tabular}

The assumption made here was that the wind speed governs the eddy diffusivity of heat transported along the temperature gradient between the sensor surface and ambient air, and the moisture correction is only associated with the fact that water vapor has a higher heat capacity $\left(1859 \mathrm{~J} \mathrm{~kg}^{-1} \mathrm{~K}^{-1}\right)$ than dry $\operatorname{air}\left(1005.5 \mathrm{~J} \mathrm{~kg}^{-1} \mathrm{~K}^{-1}\right)$, and hence the heat capacity of moist air increases accordingly with $\rho_{\mathrm{v}}$.

\subsection{Performance of the TGS 2600 sensor at $30 \mathrm{~min}$ resolution}

Using Eq. (2) yields satisfying agreement with 30 min averaged data under both typical low-Arctic summer and winter conditions (Fig. 4) with an overall $R^{2}$ of 0.424 (Table 1). When testing the linear model approach (Eq. 2) more rigorously by splitting the available data into a calibration period (years 2014-2016) and a validation period (years 2012-2013 and 2017-2018), some limitations can be seen, in particular under cold conditions, where none of the approaches performed very well in the validation period. The ANN had a more balanced performance between the calibration and validation periods, although it performed slightly less well under warm conditions $\left(T_{\mathrm{a}} \geq 0{ }^{\circ} \mathrm{C}\right)$.

A detailed inspection of four representative 7-week time periods at full $30 \mathrm{~min}$ resolution is shown in Figs. 5-8. Typical summer conditions at the beginning of this study (Fig. 5) and towards the end of the analyzed period (Fig. 6) indicate that the short-term agreement $\left(R^{2}=0.653\right.$; Fig. 5$)$ was better when the TGS sensor was still relatively new than when it was 7 years old $\left(R^{2}=0.381\right.$; Fig. 6$)$, but the variability decreased (improved) from $-42 \%$ to $-9 \%$ with no relevant difference in bias and stability $\left(0.01 \mu \mathrm{mol} \mathrm{mol}^{-1}\right.$ and $0.4 \%$ vs. $0.00 \mu \mathrm{mol} \mathrm{mol}^{-1}$ and $0.0 \%$, respectively). In winter the timing of most events is correctly captured (Fig. 7) with an $R^{2}$ of 0.445 , but the dynamics are not satisfactorily captured by the TGS sensor, indicated by a $59 \%$ underestimation of the $95 \% \mathrm{CI}$ during this midwinter period. The transition from warm to cold season (Fig. 8) shows a mixture of days when the regular diel cycle, which is typical for the warm season, is still adequately captured, but the dynamics of periods with an air temperature below $0{ }^{\circ} \mathrm{C}$ (see Fig. 4), when $\mathrm{CH}_{4}$ mole fractions tend to be highest as in winter (Fig. 7), are not adequately captured. Still, with an $R^{2}$ of 0.512 (Fig. 8) more than $50 \%$ of the variance observed in the $30 \mathrm{~min}$ averaged $\mathrm{CH}_{4}$ reference measurements is captured by the lowcost TGS 2600 sensor.

Because of the absence of local sources of carbon monoxide and other air pollutants to which the TGS 2600 sensor is also sensitive (besides $\mathrm{CH}_{4}$ ), we investigated a special case when smoke and haze from wildfires south of the Books Range polluted the air in the TFS area on 26 June 2015 and compared the performance of both TGS sensors during that day with conditions $3 \mathrm{~d}$ before that event and on the same date in the following 3 years. The net effect of increased air pollutants was an apparent small decrease in the $\mathrm{CH}_{4}$ mole fractions calculated via Eq. (2) by approximately $-0.03 \mu \mathrm{mol} \mathrm{mol}^{-1}$. At the same time the variability of the residuals increased from typically \pm 0.014 to $\pm 0.027 \mu \mathrm{mol} \mathrm{mol}^{-1}$ ( $24 \mathrm{~h}$ averages). Thus, the influence of the wildfire smoke was of the same order of magnitude as the difference between TGS-derived $\mathrm{CH}_{4}$ mole fractions and the reference instrument on most other days of the year (see Figs. 5-8). 


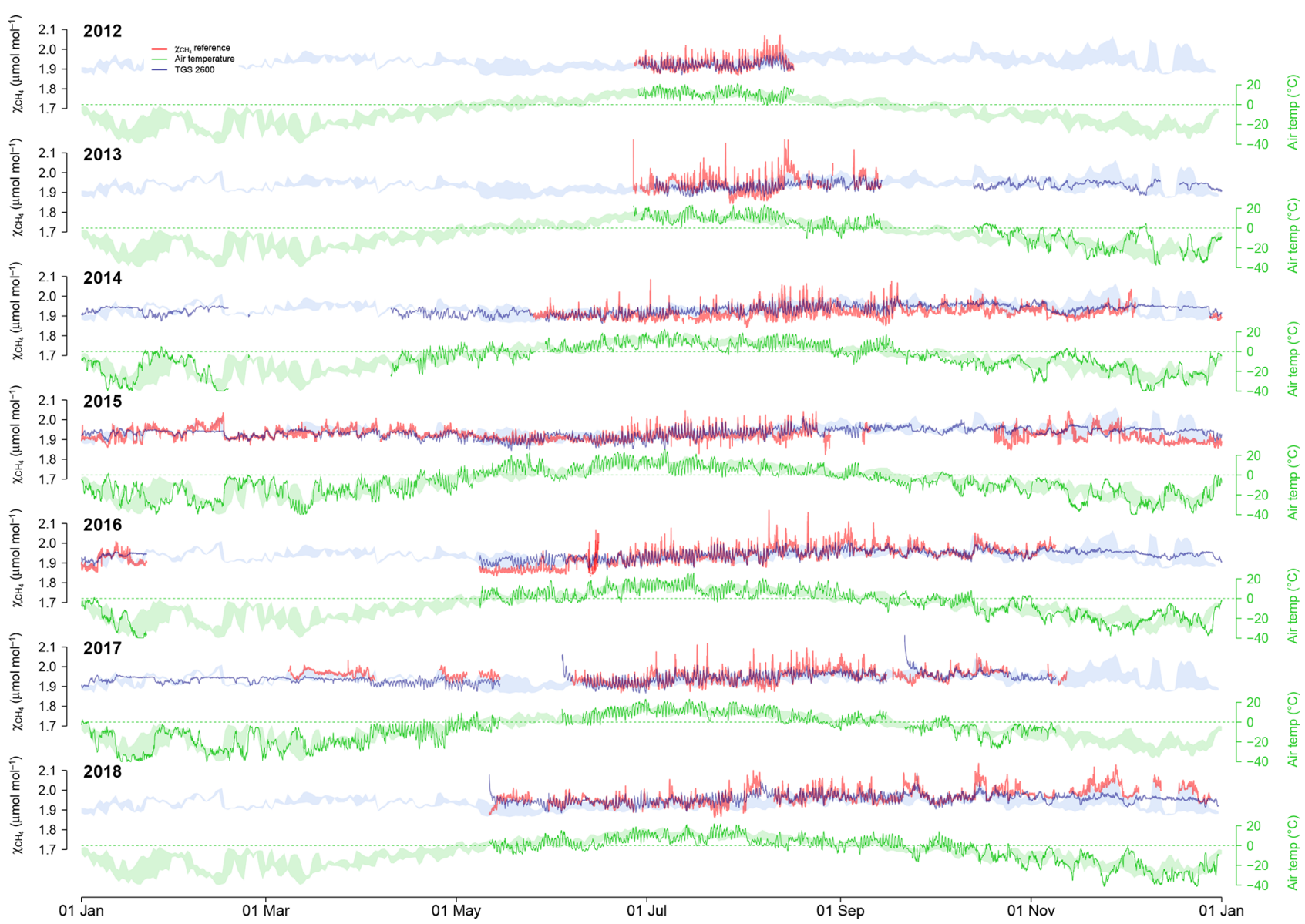

Figure 4. Overview over annual courses of 30 min averaged air temperature (green) and $\mathrm{CH}_{4}$ mole fractions (blue and red). Pale color bands show the daily interquartile range (50\% of values between the first and third quartiles) of measurements from all years. Solid lines show actual measurements. Red lines are the reference $\mathrm{CH}_{4}$ measurements, and blue lines show the $\mathrm{CH}_{4}$ mole fraction derived from TGS 2600 measurements (sensor 1). Actual measurements show 30 min mean values.

\subsection{Performance of weekly aggregated data}

The TGS 2600 is not expected to provide short-term accuracy comparable to high-quality instrumentation (see also Lewis et al., 2018). However, Eugster and Kling (2012) argued that such measurements may still provide additional insights as compared to the passive samplers described by Godbout et al. (2006a, b) by integrating over longer time frames. Thus, here we inspected the performance of weekly aggregated estimates derived from the TGS 2600 in order to inspect drift of the two sensors and their performance over the 7 -year deployment period. Note that in Eq. (2) we did not include a drift correction. Figure 9 shows weekly medians of sensor signals, the agreement with the reference signal, and the difference between the $\mathrm{CH}_{4}$ mole fractions obtained from both TGS 2600 sensors mounted at the same position (Fig. 1). The two TGS 2600 sensors (1 and 2) showed a trend in their signals of -18.8 and $-15.5 \mathrm{mV} \mathrm{yr}^{-1}$, respectively (Fig. 9a). Thus, with typical signals on the order of 200 $700 \mathrm{mV}$ (Fig. 9a) the lowest (winter) readings may no longer be measurable after 10-13 years of continuous operation, indicating the end of life of a TGS 2600.

Figure 10 shows the weekly median bias, variability, and the correlation between the weekly aggregated median diel cycle of $\mathrm{CH}_{4}$ at hourly resolution between the TGS 1 measurements and the reference. Despite the trend of the sensor signal shown in Fig. 9a and b, both the bias and variability primarily show a seasonal pattern with a slightly negative bias (around $-0.02 \mu \mathrm{mol} \mathrm{mol}^{-1}$ ) during peak growing season and a corresponding positive deviation in midwinter when temperatures can be well below $-30^{\circ} \mathrm{C}$ (Fig. 10a). The variability (Fig. 10b) shows the inverse pattern of the bias. If bias is expressed as the relative bias (i.e., stability), the stability vs. variability plot (Fig. 11) shows points lying uniformly around the line of a $-1: 1$ relationship $\left(R^{2}=0.67\right)$. This indicates that both variability and stability can be improved at the same time because there is no tradeoff visible in Fig. 11. 

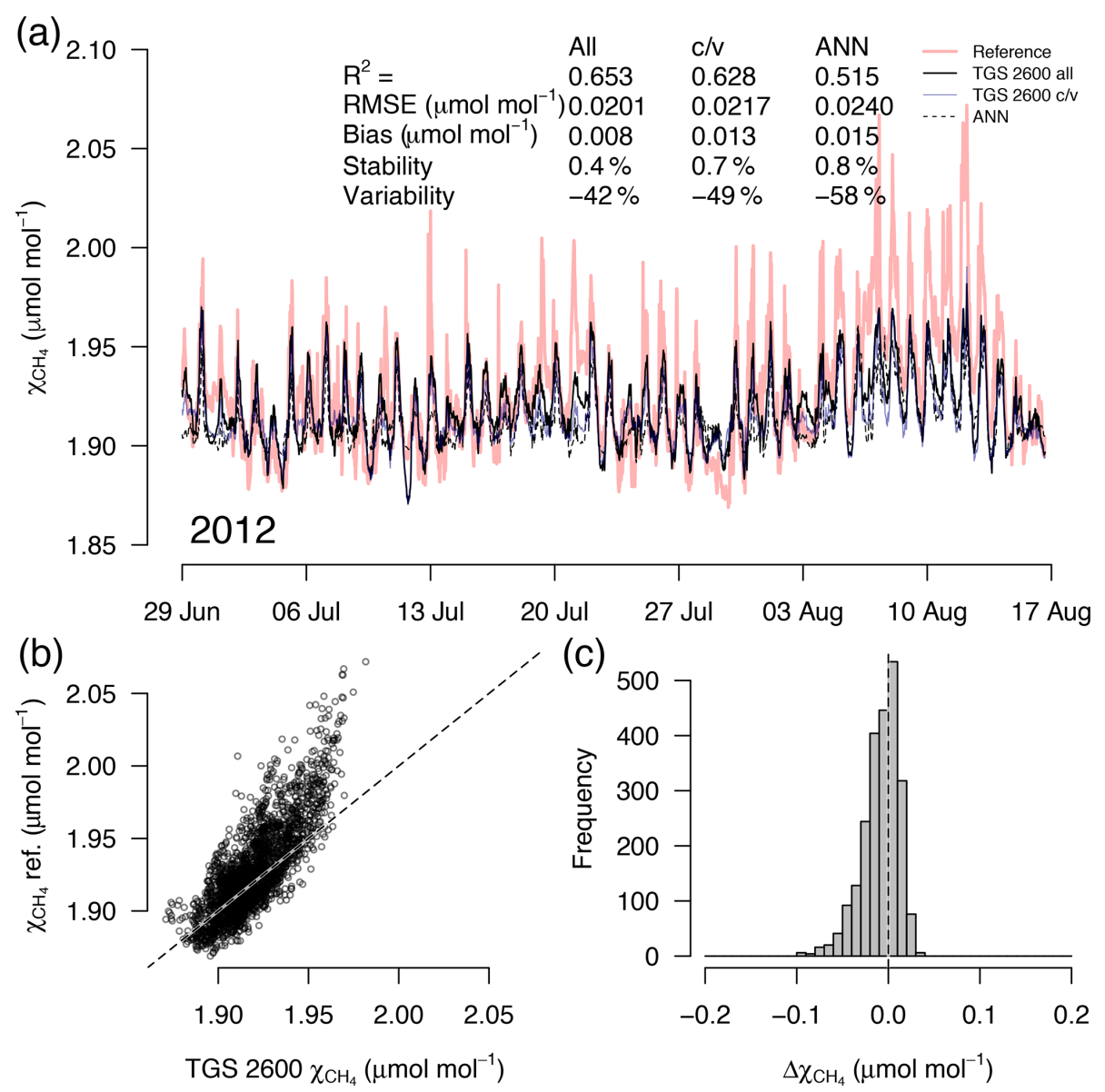

Figure 5. (a) Time series of TGS 1-derived $\mathrm{CH}_{4}$ during a 7-week snow- and ice-free period in the first year of the long-term deployment (2012), (b) correlation with reference mole fraction, and (c) residuals (TGS 2600 all minus the reference) of 30 min averaged measurements. Thin solid lines in (a) show the result when all data are used with Eq. (2), reference mole fraction is shown with a red bold line, c/v shows an alternative fit from splitting the available data into a calibration and a validation part, and the dashed line shows the performance of an artificial neural network (ANN) fit. This example belongs to the validation period of the TGS $2600 \mathrm{c} / \mathrm{v}$ and ANN fits.

\subsection{Linear trend and drift estimates}

All linear trend estimates were statistically significant (see Sect. 2.4). However, our measurements started with warmseason measurements only (2012-2014) that were successively expanded to include cold-season measurements. Thus, all interpretation of the trends and drifts presented here should be considered with caution given the long gaps in data due to the technical challenges of operating such equipment under adverse winter conditions. The $\mathrm{CH}_{4}$ mole fraction trend observed with the high-quality reference measurements was $10.1 \mathrm{nmol} \mathrm{mol}^{-1} \mathrm{yr}^{-1}$. This is 2.5 times the trend observed from 2005 to 2011 by NOAA ( $28.6 \pm 0.9 \mathrm{nmol} \mathrm{mol}^{-1}$ or $4.09 \mathrm{nmol} \mathrm{mol}^{-1} \mathrm{yr}^{-1}$; Table 2.1 in Hartmann et al., 2014) but of the same order of magnitude reported by Nisbet et al. (2014) for 2013 (last year covered by that study) for latitudes north of the Tropic of Cancer. Thus, this trend may be real, and hence all trends seen in low-cost sensor signals are not necessarily solely an artifact of such sensors. However, it remains a challenge to deduce the true trend in $\mathrm{CH}_{4}$ mole fractions over longer time periods using such a low-cost sensor because of drifting signals. Thus, we inspected the drift of the TGS 2600-derived mole fraction with respect to the (true) $\mathrm{CH}_{4}$ trend observed with the high-quality reference instrument. These drifts appear to be smaller than the true trend but are still considerable: the bias of TGS-derived $\mathrm{CH}_{4}$ mole fractions drifted by $4-6 \mathrm{nmol} \mathrm{mol}^{-1} \mathrm{yr}^{-1}(40 \%-60 \%$ of actual trend), and variability drifted by $-0.24 \% \mathrm{yr}^{-1}$. They provide encouraging results suggesting that with occasional (infrequent) calibration with a high-quality standard, e.g., using a traveling standard operating during a few good days with adequate coverage of the near-surface diel cycle of $\mathrm{CH}_{4}$, TGS 2600 measurements might be suitable for the monitoring of $\mathrm{CH}_{4}$ mole fractions in other areas as well. As shown in Fig. 10c the correlation of median diel cycles between TGS estimates and $\mathrm{CH}_{4}$ reference measurements is one of the weak points in the current performance of the TGS 2600 sensors. Furthermore, we observed a significant 

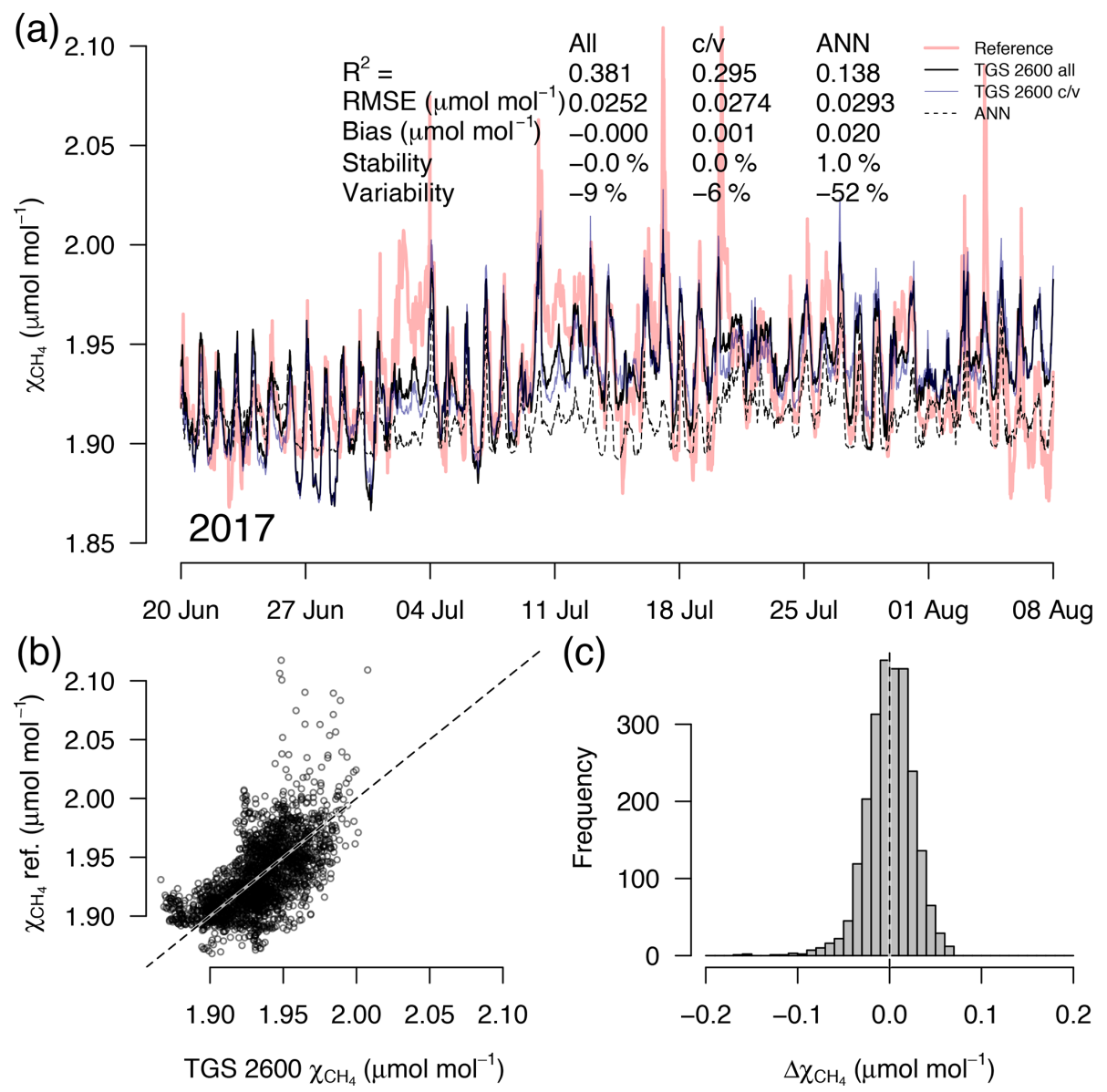

Figure 6. As in Fig. 5 but with measurements from a 7-week snow- and ice-free period in 2017 at a sensor age of 7 years. This example belongs to the validation period of the TGS $2600 \mathrm{c} / \mathrm{v}$ and ANN fits.

negative trend of the correlation coefficient of $-0.051 \mathrm{yr}^{-1}$ (Fig. 10c). However, the key finding is that the typical diel cycle during the warm season (air temperature $>0{ }^{\circ} \mathrm{C}$ ) disappears during winter conditions (Figs. 4, 7), and thus separate transfer functions for warm and cold temperatures might be a solution for future studies (Table 1). Our Eq. (2) is thus intentionally derived from the entire dataset to provide a starting point for more elaborate fine-tuning in projects where this is desired.

\subsection{Potential of using artificial neural networks}

Casey et al. (2019) found that artificial neural networks (ANNs) outperformed linear models in mitigating curvature and linear trends in trace gas measurements when used with the same set of input variables during a 3-month comparison period. To inspect the potential of ANNs at our Arctic long-term dataset, we added the ANN results to Figs. 5-8. In summer (Figs. 5, 6) we did not find a substantial difference between an ANN and the linear approach of Eq. (2) in terms of root mean square error (RMSE) or $R^{2}$ between predicted and measured $\mathrm{CH}_{4}$ mole fractions (Table 1). In win- ter, with temperatures below freezing, the ANN performed clearly better in the validation than the linear approach, but both approaches remained unsatisfactory $\left(R^{2}<0.1\right)$ despite the fact that both approaches were similar in the calibration period $\left(R^{2} \approx 0.3\right.$, Table 1$)$.

During the warm period we found cases where the ANN was much better in capturing a specific daily feature, as for example on 11 July 2012 (Fig. 5a), when the daily minimum was nicely captured by the ANN, but the linear model was much too low. Contrastingly, in 2017 (Fig. 6a) periods could be found when the daily dynamics were correctly captured by the ANN but at too low of mixing ratios (e.g., 1018 July 2017; Fig. 6a). It should be noted that at this latitude the sun does not set between 24 May and 20 July; thus nocturnal conditions are clearly different from conditions at lower latitudes such as the ones investigated by Casey et al. (2019). Similarly, the transition from warm to cold season (Fig. 8) was challenging with both the linear model and ANN approach. We have only used two variables, $T_{\mathrm{a}}$ and humidity, that according to manufacturer specifications (Figaro, 2005a, b) influence the TGS 2600 sensor signal. In reality, the same 

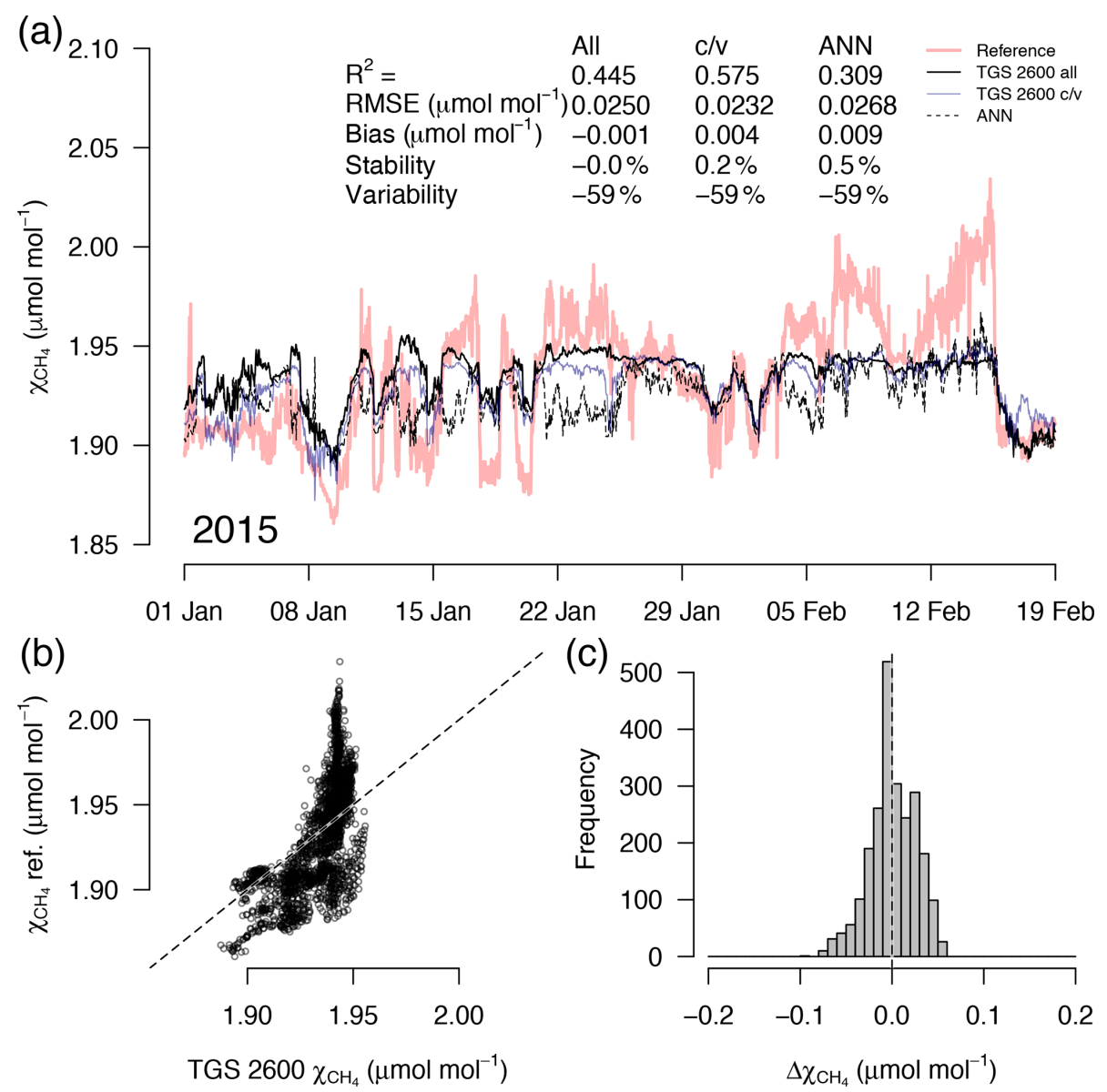

Figure 7. As in Fig. 5 but with measurements from a 7-week period in midwinter with temperatures plunging down to $-40{ }^{\circ} \mathrm{C}$. $\mathrm{High}_{\mathrm{CH}} \mathrm{CH}_{4}$ mole fractions coincide with the coldest temperatures (see Fig. 4). This example belongs to the validation period of the TGS $2600 \mathrm{c} / \mathrm{v}$ and ANN fits.

two variables also influence the $\mathrm{CH}_{4}$ production in waterlogged ecosystems and thus contribute to the true $\mathrm{CH}_{4}$ signal in addition to the cross-sensitivity, which we try to correct with Eq. (2).

An ANN that can separate the effect of ambient variations of $\mathrm{CH}_{4}$ mole fractions from the artifact of cross-sensitivity of the TGS 2600 to $T_{\mathrm{a}}$ and humidity may however outperform a linear model approach in future studies if more potentially important driving variables are included than only those specified by the manufacturer (Figaro, 2005a, b).

\subsection{Suggestions for future work}

The interquartile ranges and $95 \%$ confidence intervals of each air temperature (Fig. 12a) or absolute humidity bin (Fig. 12b) are very similar over a wide range of temperatures and humidity levels but tend to become more variable in bins with few data (i.e., lowest and highest temperatures and highest absolute humidities in Fig. 12). Deviations are generally constrained within $\pm 0.1 \mu \mathrm{mol} \mathrm{mol}{ }^{-1}$ or better but with higher variability at both temperature ends, where data cover- age is poor (gray bars at bottom of Fig. 12a) as temperatures below $-30^{\circ} \mathrm{C}$ were not frequently covered due to technical problems with the measurement station and summer temperatures above $20^{\circ} \mathrm{C}$ are still rather rare at this low-Arctic latitude (Hobbie and Kling, 2014). A slightly different picture emerges for low absolute humidity: $56 \%$ of measurements are at lower humidities than the saturation humidity at $0^{\circ} \mathrm{C}$ $\left(0.0049 \mathrm{~kg} \mathrm{~m}^{-3}\right)$; thus the rather homogenous variances at low humidity (Fig. 12b) indicate that humidity is not of concern at low temperatures, and future attempts for improvements should rather focus on humidity above $0.01 \mathrm{~kg} \mathrm{~m}^{-3}$ and temperatures above $20^{\circ} \mathrm{C}$ that are not normally found in the Arctic.

Based on physical considerations one might expect that specific humidity or water vapor mixing ratio instead of absolute humidity could lead to further improvements because absolute humidity still depends on temperature. However, our tests have not indicated a relevant gain of information or accuracy of prediction, but future work should also try to find a better physical correction model than the purely empirical one used here based on manufacturer information. 

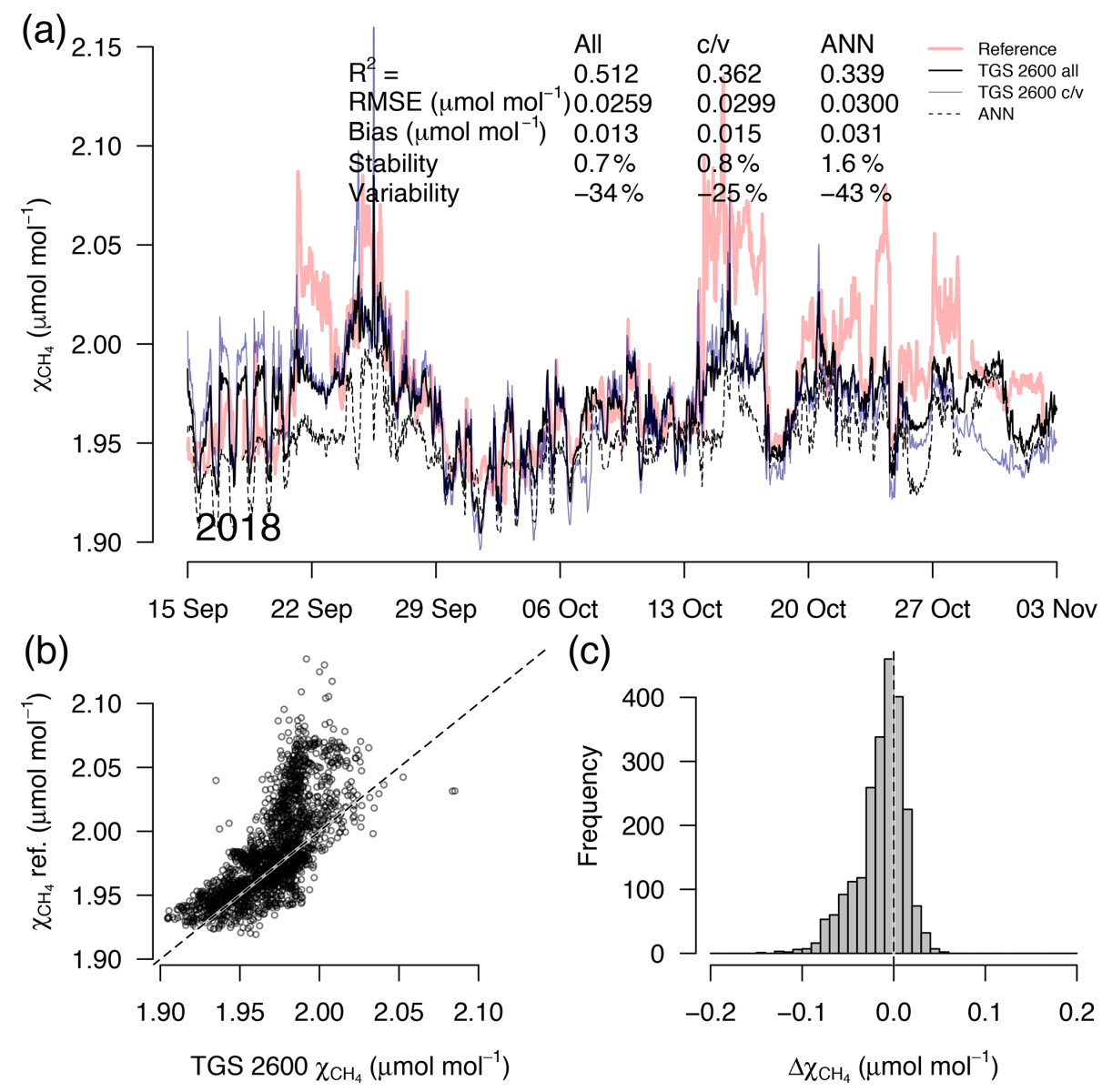

Figure 8. As in Fig. 5 but with measurements from a 7-week period during the transition from fall to early winter. This example belongs to the validation period of the TGS $2600 \mathrm{c} / \mathrm{v}$ and ANN fits.

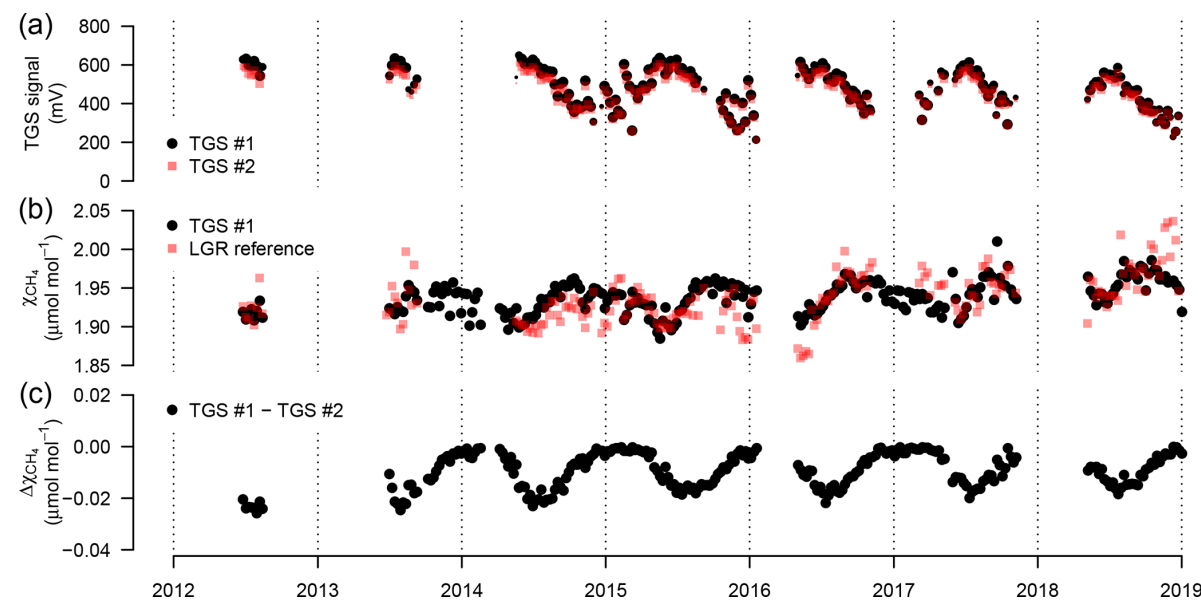

Figure 9. (a) Weekly median sensor signals from both TGS 2600 sensors, (b) $\mathrm{CH}_{4}$ derived with Eq. (2) for TGS sensor 1 and measured by the Los Gatos Research reference instrument, and (c) absolute difference between the two TGS 2600 sensors. The signals from both sensors were converted to $\mathrm{CH}_{4}$ using Eq. (2) parameterized with data from TGS sensor 1. Symbol size is proportional to relative data coverage. 


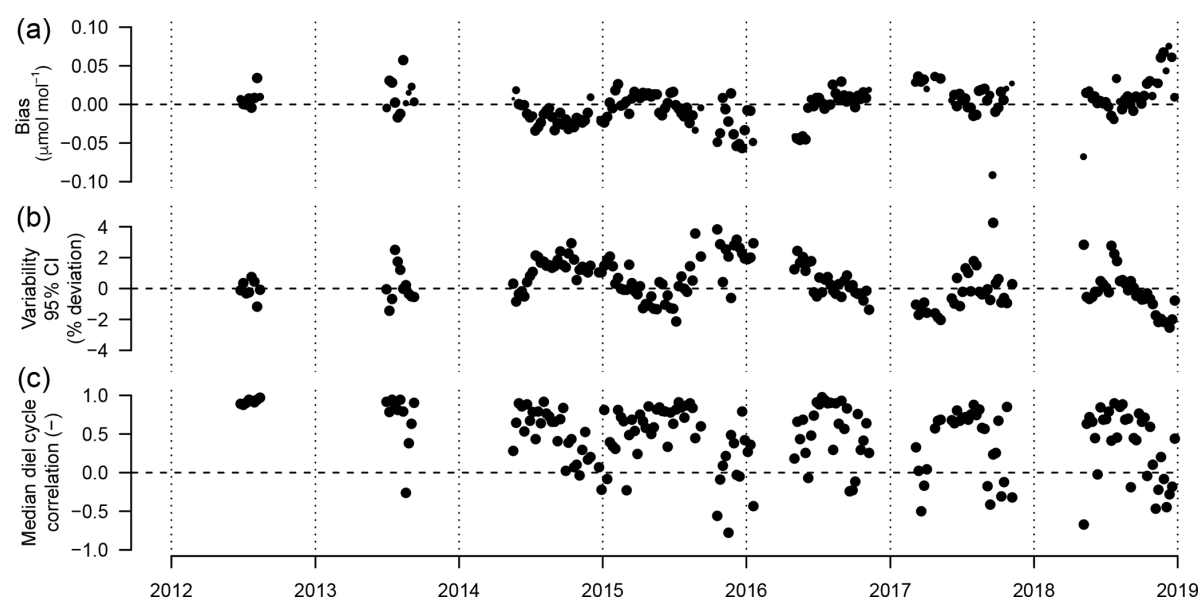

Figure 10. (a) Weekly median bias, (b) median variability, and (c) correlation between weekly median diel cycles of TGS 2600 sensor 1 and the reference. Symbol size is proportional to relative data coverage.

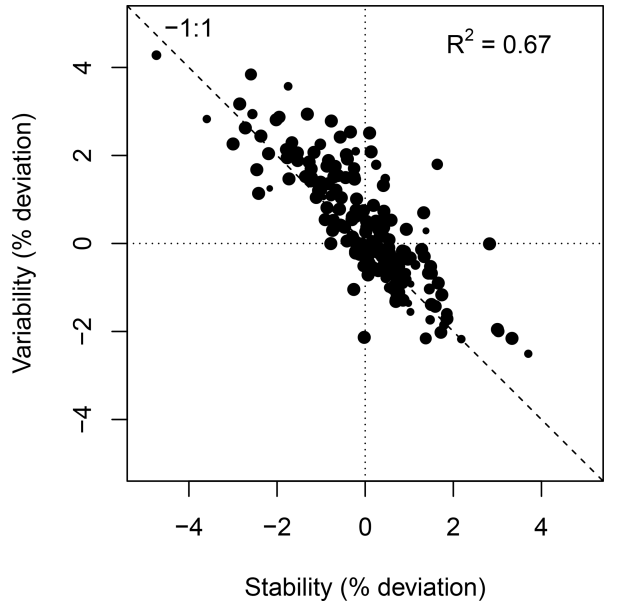

Figure 11. Variability and stability (relative bias) of weekly median TGS 2600 sensor 1-derived $\mathrm{CH}_{4}$ mole fractions are inversely related and plotted along the $-1: 1$ line. Symbol size is proportional to relative data coverage.

Another approach was taken by van den Bossche et al. (2017), who performed an in-depth laboratory calibration of the very similar but less sensitive Figaro TGS 2611-E00 sensor (the manufacturer only specifies a response above $300 \mathrm{~mol} \mathrm{~mol}^{-1} \mathrm{CH}_{4}$; Figaro, 2013) at different temperatures and levels of relative humidity over a $\mathrm{CH}_{4}$ calibration range starting at $\approx 2 \mu \mathrm{mol} \mathrm{mol}^{-1}$ ambient mole fraction up to $10 \mu \mathrm{mol} \mathrm{mol}^{-1} \mathrm{CH}_{4}$. Despite the effort, the residual mole fractions remained large (range of ca. $-1.5 \mu \mathrm{mol} \mathrm{mol}^{-1}$ to $+1.1 \mu \mathrm{mol} \mathrm{mol}^{-1}$ ) - too large for the application we present here. Our efforts to calibrate our TGS 2600 sensors in a laboratory climate chamber in a similar way were not satisfactory (Eugster, unpublished), hence our approach presented here to determine the sensor behavior from long-term outdoor measurements under real-world conditions. Contrastingly, Kneer
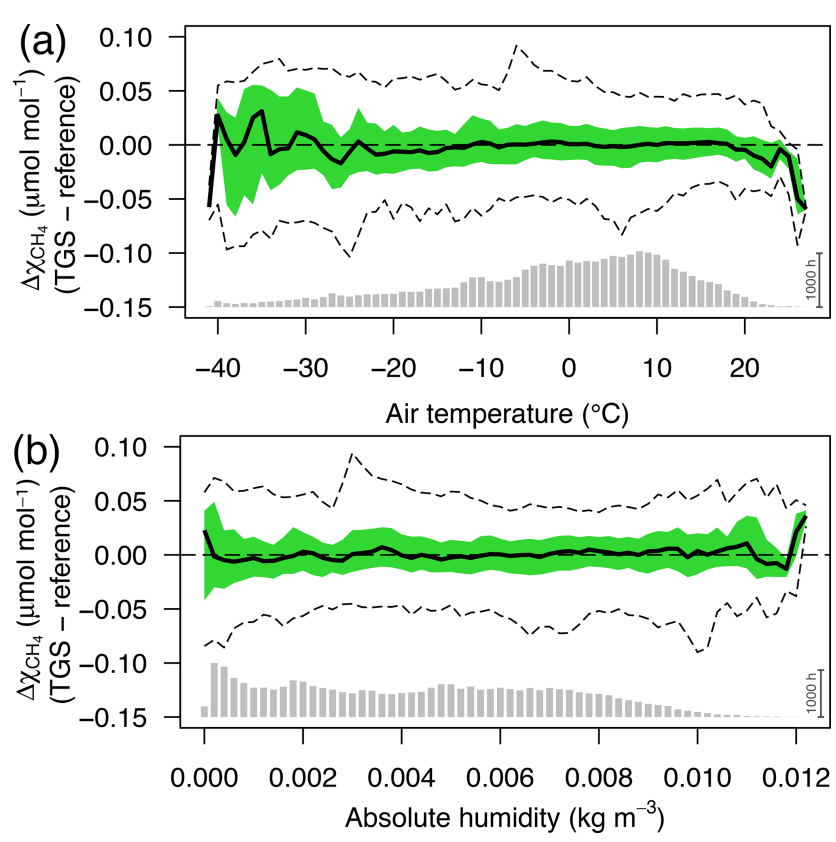

Figure 12. Residuals of $30 \mathrm{~min}$ averaged TGS 2600 vs. reference $\mathrm{CH}_{4}$ measurements as a function of (a) air temperature and (b) absolute humidity. Colored areas show the interquartile range $(50 \% \mathrm{CI})$, bold lines show the median, and dashed lines show the bin-averaged $95 \%$ confidence interval. Bin size was $1{ }^{\circ} \mathrm{C}$ and $0.0002 \mathrm{~kg} \mathrm{~m}^{-3}$, respectively. Gray bars at the bottom show the number of $30 \mathrm{~min}$ averages in each bin; the scale bar $(1000 \mathrm{~h})$ on the right specifies their size.

et al. (2014) are convinced that "to be of use for advanced applications metal-oxide gas sensors need to be carefully prepared and characterized in laboratory environments prior to deployment". While this is theoretically correct, it remains difficult to carry out laboratory treatments from -41 to $27^{\circ} \mathrm{C}$ as would be required for our Arctic site. The data we present 
indicate that it is most likely absolute humidity (or specific humidity or mixing ratio), not relative humidity, that should be used for such calibrations, which in principle should provide the best quality results if the relevant factors are known and can be included in the calibration setup. Ideally, manufacturers should carry out both laboratory tests and field trials and provide the necessary correction functions together with sensors. However, due to the expense and time it takes to carry out long tests, be it in the laboratory or in the field, the present development goes in the direction of collocation studies (Piedrahita et al., 2014) en route to certification of sensors (Nick Martin, NPL, UK, personal communication, 2020), similar to what we have done in the Arctic.

The TGS 2600 sensor's best performance is in applications where passive samplers would be another option (see also Eugster and Kling, 2012). Contrastingly, using the TGS 2600 for short-term measurements (resolution of seconds to minutes) has not yet led to satisfactory results (Kirsch, 2012; Falabella et al., 2018). In our dataset we found that adding wind speed to the empirical linear model slightly improved the model fit during the warm season, but because no reliable continuous winter wind speed measurements were possible at the TWE site we did not include wind speed in our Eq. (2). However, this may be a key component for understanding the variability of TGS 2600 measurements when flying an unmanned aerial vehicle (UAV) where turbulent conditions may change within seconds to minutes. To address this additional factor, we used the heat loss model given in Eq. (3). However, although this approach is more mechanistic than Eq. (2), it was much less able to predict $\mathrm{CH}_{4}$ mole fraction from TGS 2600 measurements than the empirical linear model and ANN approaches (Table 1). But in order to make further progress on improving the transfer function from TGS 2600 signals to defensible $\mathrm{CH}_{4}$ mole fractions it will be essential to increase our understanding of the physical processes that influence such measurements. This is not an easy task since there is substantial proprietary knowledge that the manufacturer has not revealed. Newer, promising developments are underway that work with a mixed-potential sensor using tindoped indium oxide and platinum electrodes in combination with yttria-stabilized zirconia electrolytes that show a logarithmic signal range of $0-10 \mathrm{mV}$ for the $1-3 \mu \mathrm{mol} \mathrm{mol}^{-1} \mathrm{CH}_{4}$ range of interest for ambient air studies (Sekhar et al., 2016). The basic principle that the active metal oxide is charged with $\mathrm{O}_{2}$ (or $\mathrm{O}^{2-}$ ), which then oxidizes $\mathrm{CH}_{4}$, seems to be similar to the $\mathrm{SnO}_{2}$-based TGS 2600; thus there is a good chance that our findings for the TGS 2600 are also useful for assessing the performance of newer solid-state sensors with different active materials.

\section{Conclusions}

We present the first long-term deployment of two identical, low-cost TGS 2600 sensors that show a sensitivity to ambi- ent levels of $\mathrm{CH}_{4}$ (here: range of $1.824-2.682 \mu \mathrm{mol} \mathrm{mol}^{-1}$ as measured by a high-quality Los Gatos Research reference instrument). We suggest a new transfer function to correct the TGS 2600 signal for cross-sensitivity to ambient temperature and humidity that also yields satisfactory results under cold climate (Arctic) conditions with temperatures down to $-40^{\circ} \mathrm{C}$. This was only possible by using absolute humidity and not relative humidity for the correction. With this correction determined over the entire 2012-2018 data period, the 30 min average $\mathrm{CH}_{4}$ mole fraction could be derived from TGS 2600 measurements within $\pm 0.1 \mu \mathrm{mol} \mathrm{mol}^{-1}$. The two completely different regimes of diel $\mathrm{CH}_{4}$ mole fraction variations during the cold season (typically with a snow cover and frozen surface waters) and the warm season (when plants are active in the low Arctic) suggest that further improvements can be obtained by more specifically developing separate transfer functions for cold and warm conditions.

We consider the quality of TGS 2600 -derived $\mathrm{CH}_{4}$ estimates adequate if aggregated over reasonable periods (e.g., days or one week), but caution should be taken with application where short-term response is of key relevance (e.g., within seconds to minutes as required for mobile measurements with UAVs). The deterioration of the sensor signal over time indicates that a TGS 2600 that is operated under ambient conditions as in our deployment at a low-Arctic site in northern Alaska (Toolik wet sedge site) has an estimated lifetime of ca. 10-13 years. Thus, there is potential beyond preliminary studies if the TGS 2600 sensor is adequately calibrated and placed in a suitable environment where crosssensitivities to gases other than $\mathrm{CH}_{4}$ are of no concern.

Data availability. The data used in this study can be downloaded from the Environmental Data Initiative (EDI) portal via https://doi.org/10.6073/pasta/dddeb05b2806e2f5788fadd6fc590ef1 (Eugster et al., 2020). The statistical fits shown in Figs. 5-8 are made available via the ETH Zurich Research Collection: https://doi.org/10.3929/ethz-b-000369689 (Eugster and Eugster, 2020).

Author contributions. WE, JL, and GWK designed the study, set up the instrumentation, and serviced the site. WE carried out the main analyses. JE helped with the main analyses as well as set up and carried out the ANN calculations. WE wrote the manuscript, and all coauthors worked, commented, and revised various versions.

Competing interests. The authors declare that they have no conflict of interest.

Disclaimer. The authors are independent from the producers of the instruments and sensors referenced in this article, and thus the authors do not have a commercial interest in promoting any of the mentioned products. 
Acknowledgements. We thank Jeb Timm, Colin Edgar, and other members of the Toolik Field Station science support staff for field help under difficult conditions. We also thank support staff from CPS for help with power supplies in addition to the technicians and students supported by several NSF grants and several students supported by the NSF-REU program for help in the field over the years.

We acknowledge support received from Arctic LTER grants (grant nos. NSF-DEB-1637459, 1026843, 1754835, and NSF-PLR 1504006) and supplemental funding from the NSF-NEON and OPP-AON programs. Gaius R. Shaver (MBL) is acknowledged for initiating the study and supporting our activities in all aspects. ETH is acknowledge for supporting the purchase of the Fast Greenhouse Gas Analyzer that replaced the older Fast Methane Analyzer in 2016 (grant no. 0-43683-11).

We thank the two anonymous reviewers for their careful and helpful assessments.

Review statement. This paper was edited by Huilin Chen and reviewed by two anonymous referees.

\section{References}

Aghagoli, Z. and Ardyanian, M.: Synthesis and study of the structure, magnetic, optical and methane gas sensing properties of cobalt doped zinc oxide microstructures, J. Mater. Sci., 29, 71307141, https://doi.org/10.1007/s10854-018-8701-4, 2018.

Akritas, M. G., Murphy, S. A., and Lavalley, M. P.: The Theil-Sen estimator with doubly censored data and applications to astronomy, J. Am. Stat. Assoc., 90, 170-177, https://doi.org/10.1080/01621459.1995.10476499, 1995.

Casey, J. G., Collier-Oxandale, A., and Hannigan, M.: Performance of artificial neural networks and linear models to quantify 4 trace gas species in an oil and gas production region with low-cost sensors, Sensor. Actuat. B-Chem., 283, 504-514, https://doi.org/10.1016/j.snb.2018.12.049, 2019.

Castell, N., Dauge, F. R., Schneider, P., Vogt, M., Lerner, U., Fishbain, B., Broday, D., and Bartonova, A.: Can commercial low-cost sensor platforms contribute to air quality monitoring and exposure estimates?, Environ. Int., 99, 293-302, https://doi.org/10.1016/j.envint.2016.12.007, 2017.

Collier-Oxandale, A., Casey, J. G., Piedrahita, R., Ortega, J., Halliday, H., Johnston, J., and Hannigan, M. P.: Assessing a low-cost methane sensor quantification system for use in complex rural and urban environments, Atmos. Meas. Tech., 11, 3569-3594, https://doi.org/10.5194/amt-11-3569-2018, 2018.

Eugster, W. and Eugster, J.: Statistical fits shown in Figs. 5-8, ETH Zürich, https://doi.org/10.3929/ethz-b-000369689, 2020.

Eugster, W. and Kling, G. W.: Performance of a low-cost methane sensor for ambient concentration measurements in preliminary studies, Atmos. Meas. Tech., 5, 1925-1934, https://doi.org/10.5194/amt-5-1925-2012, 2012.

Eugster, W., Kling, G., and Laundre, J.: Climate data from Arctic LTER Toolik Inlet Wet Sedge site, Toolik Field Station, Alaska 2012 to 2018, ver 1, Environmental Data Initiative, https://doi.org/10.6073/pasta/dddeb05b2806e2f5788fadd6fc590ef1, 2020 .
Falabella, A. D., Wallin, D. O., and Lund, J. A.: Application of a customizable sensor platform to detection of atmospheric gases by UAS, in: 2018 International Conference on Unmanned Aircraft Systems (ICUAS), IEEE, https://doi.org/10.1109/icuas.2018.8453480, 2018.

Figaro: TGS 2600 - for the detection of air contaminants, Online product data sheet, Rev. 01/05, available at: http://www.figarosensor.com/product/docs/TGS2600B00\% 20\%280913\%29.pdf (last access: 29 September 2019), 2005 a.

Figaro: Technical information on usage of TGS sensors for toxic and explosive gas leak detectors, Online product information sheet, Rev. 03/05, available at: https://www. electronicaembajadores.com/datos/pdf2/ss/ssga/tgs.pdf (last access: 29 September 2019), 2005 b.

Figaro: TGS 2611 - for the detection of methane, Online product data sheet, Rev. 10/13, available at: http://www.figarosensor. com/products/docs/TGS\%202611C00\%281013\%29.pdf (last access: 29 September 2019), 2013.

Godbout, S., Phillips, V. R., and Sneath, R. W.: Passive flux samplers to measure nitrous oxide and methane emissions from agricultural sources, Part 1: Adsorbent selection, Biosyst. Eng., 94, 587-596, https://doi.org/10.1016/j.biosystemseng.2006.04.014, $2006 a$.

Godbout, S., Phillips, V. R., and Sneath, R. W.: Passive flux samplers to measure nitrous oxide and methane emissions from agricultural sources, Part 2: Desorption improvements, Biosyst. Eng., 95, 1-6, https://doi.org/10.1016/j.biosystemseng.2006.05.007, 2006 b.

Hartmann, D. L., Tank, A. M. K., Rusticucci, M., Alexander, L., Broennimann, S., Charabi, Y. A.-R., Dentener, F., Dlugokencky, E., Easterling, D., Kaplan, A., Soden, B., Thorne, P., Wild, M., and Zhai, P.: Observations: Atmosphere and Surface, chap. 2, IPCC AR5, Cambridge University Press, Cambridge, UK and New York, NY, USA, 2014.

Hobbie, J. E. and Kling, G. W. (Eds.): Alaska's Changing Arctic: Ecological Consequences for Tundra, Streams, and Lakes, LongTerm Ecological Research (LTER) Network Series, Oxford University Press, New York, USA, 331 pp., 2014.

Hu, J., Gao, F., Zhao, Z., Sang, S., Li, P., Zhang, W., Zhou, X., and Chen, Y.: Synthesis and characterization of Cobalt-doped ZnO microstructures for methane gas sensing, Appl. Surf. Sci., 363, 181-188, https://doi.org/10.1016/j.apsusc.2015.12.024, 2016.

Kirsch, O.: Entwicklung, Bau und Einsatz einer autonomen Drohne zur Messung von Gaskonzentrationen in der Luft, Maturarbeit mit beteiligung am wettbewerb schweizer jugend forscht, Kantonsschule Chur, Chur, Switzerland, 17 pp., 2012.

Kneer, J., Eberhardt, A., Walden, P., Pérez, A. O., Wöllenstein, J., and Palzer, S.: Apparatus to characterize gas sensor response under real-world conditions in the lab, Rev. Sci. Instr., 85, 055006, https://doi.org/10.1063/1.4878717, 2014.

Lewis, A. C., von Schneidemesser, E., and Peltier, R.: Lowcost sensors for the measurement of atmospheric composition: overview of topic and future applications, Tech. Rep. WMO-No. 1215, WMO, Geneva, Switzerland, available at: http://www.wmo.int/pages/prog/arep/gaw/documents/ Low_cost_sensors_post_review_final.pdf (last access: 24 February 2019), 2018.

Marchetto, A., Rogora, M., and Arisci, S.: Trend analysis of atmospheric deposition data: A comparison of 
statistical approaches, Atmos. Environ., 64, 95-102, https://doi.org/10.1016/j.atmosenv.2012.08.020, 2013.

Nisbet, E. G., Dlugokencky, E. J., and Bousquet, P.: Methane on the rise - again, Science, 343, 493-495, https://doi.org/10.1126/science.1247828, 2014.

Pedregosa, F., Varoquaux, G., Gramfort, A., Michel, V., Thirion, B., Grisel, O., Blondel, M., Prettenhofer, P., Weiss, R., Dubourg, V., Vanderplas, J., Passos, A., Cournapeau, D., Brucher, M., Perrot, M., and Duchesnay, É.: Scikit-learn: machine learning in Python, J. Mach. Learning Res., 12, 2825-2830, 2011.

Piedrahita, R., Xiang, Y., Masson, N., Ortega, J., Collier, A., Jiang, Y., Li, K., Dick, R. P., Lv, Q., Hannigan, M., and Shang, L.: The next generation of low-cost personal air quality sensors for quantitative exposure monitoring, Atmos. Meas. Tech., 7, 3325-3336, https://doi.org/10.5194/amt-7-3325-2014, 2014.

R Core Team: R: A Language and Environment for Statistical Computing, R Foundation for Statistical Computing, Vienna, Austria, available at: https://www.R-project.org/ (last access: 14 May 2020), 2018.

Sekhar, P. K., Kysar, J., Brosha, E. L., and Kreller, C. R.: Development and testing of an electrochemical methane sensor, Sensor. Actuat. B-Chem., 228, 162-167, https://doi.org/10.1016/j.snb.2015.12.100, 2016.
Shamasunder, B., Collier-Oxandale, A., Blickley, J., Sadd, J., Chan, M., Navarro, S., Hannigan, M., and Wong, N.: CommunityBased Health and Exposure Study around Urban Oil Developments in South Los Angeles, Int. J. Env. Res. Pub. He., 15, 138, https://doi.org/10.3390/ijerph15010138, 2018.

Thanh Duc, N., Silverstein, S., Wik, M., Crill, P., Bastviken, D., and Varner, R. K.: Greenhouse gas flux studies: An automated online system for gas emission measurements in aquatic environments, Hydrol. Earth Syst. Sci. Discuss., https://doi.org/10.5194/hess2019-83, in review, 2019.

van den Bossche, M., Rose, N. T., and De Wekker, S. F. J.: Potential of a low-cost gas sensor for atmospheric methane monitoring, Sensor. Actuat. B-Chem., 238, 501-509, https://doi.org/10.1016/j.snb.2016.07.092, 2017.

Walker, D. A. and Everett, K. R.: Loess Ecosystems of Northern Alaska: Regional Gradient and Toposequence at Prudhoe Bay, Ecol. Monogr., 61, 437-464, 1991.

WMO: Global Atmosphere Watch Measurements Guide, Tech. Rep. TD No. 1073, World Meteorological Organisation, available at: http://citeseerx.ist.psu.edu/viewdoc/download?doi=10.1. 1.360.4587\&rep=rep1\&type=pdf (last access: 14 May 2020), 87 pp., 2001. 